\title{
Dissecting the transcriptional regulatory networks of promoter-associated noncoding RNAs in development and cancer
}

\author{
Lidia Chellini ${ }^{1 \dagger}$, Valentina Frezza ${ }^{1 \dagger}$ and Maria Paola Paronetto ${ }^{1,2^{*}}$
}

\begin{abstract}
In-depth analysis of global RNA sequencing has enabled a comprehensive overview of cellular transcriptomes and revealed the pervasive transcription of divergent RNAs from promoter regions across eukaryotic genomes. These studies disclosed that genomes encode a vast repertoire of RNAs beyond the well-known protein-coding messenger RNAs. Furthermore, they have provided novel insights into the regulation of eukaryotic epigenomes, and transcriptomes, including the identification of novel classes of noncoding transcripts, such as the promoterassociated noncoding RNAs (pancRNAs).

PancRNAs are defined as transcripts transcribed within few hundred bases from the transcription start sites (TSSs) of protein-coding or non-coding genes. Unlike the long trans-acting ncRNAs that regulate expression of target genes located in different chromosomal domains and displaying their function both in the nucleus and in the cytoplasm, the pancRNAs operate as cis-acting elements in the transcriptional regulation of neighboring genes. PancRNAs are very recently emerging as key players in the epigenetic regulation of gene expression programs in development and diseases.

Herein, we review the complex epigenetic network driven by pancRNAs in eukaryotic cells, their impact on physiological and pathological states, which render them promising targets for novel therapeutic strategies.
\end{abstract}

Keywords: Promoter-associated noncoding RNA (pancRNA), Chromatin remodeling, Epigenome, Development, Cancer

\section{Background}

Transcription initiation is a tightly regulated process that involves remodeling of nucleosome organization and recruitment of transcription factors and the RNA Polymerase II (RNAPII) on the transcription units. Recent advances based on RNA sequencing efforts documented

\footnotetext{
* Correspondence: mariapaola.paronetto@uniroma4.it

'Lidia Chellini and Valentina Frezza contributed equally to this work.

'Laboratory of Molecular and Cellular Neurobiology, IRCCS Santa Lucia Foundation, 00143 Rome, Italy

2Department of Movement, Human and Health Sciences, University of Rome "Foro Italico", Piazza Lauro de Bosis 6, 00135 Rome, Italy
}

several classes of long and short noncoding RNAs transcribed in the promoter regions proximal the transcription start sites (TSS) of most annotated genes, bona fide involved in the regulation of transcription initiation [1]. Among them, the promoter-associated noncoding RNAs (named interchangeably pancRNAs or pncRNAs) have now been described in all eukaryotic species, from yeast to human [1-9]. PancRNAs are defined as transcripts transcribed within a few hundred bases from the TSSs of protein-coding or non-coding genes. Unlike the long trans-acting ncRNAs that regulate expression of target genes located in different chromosomal domains or even

(c) The Author(s). 2020 Open Access This article is licensed under a Creative Commons Attribution 4.0 International License, which permits use, sharing, adaptation, distribution and reproduction in any medium or format, as long as you give appropriate credit to the original author(s) and the source, provide a link to the Creative Commons licence, and indicate if changes were made. The images or other third party material in this article are included in the article's Creative Commons licence, unless indicated otherwise in a credit line to the material. If material is not included in the article's Creative Commons licence and your intended use is not permitted by statutory regulation or exceeds the permitted use, you will need to obtain permission directly from the copyright holder. To view a copy of this licence, visit http://creativecommons.org/licenses/by/4.0/ The Creative Commons Public Domain Dedication waiver (http://creativecommons.org/publicdomain/zero/1.0/) applies to the data made available in this article, unless otherwise stated in a credit line to the data. 
in different chromosomes, the pancRNAs by definition operate as cis-acting elements in the transcriptional regulation of neighboring genes [10]. Notably, these noncoding transcripts often show tissue specificity, suggesting regulated expression and functional involvement in biological processes [10].

Here we are reviewing current knowledge about cisacting ncRNAs transcribed from promoter regions of protein-coding genes and their impact on chromatin signature and gene expression programs, in both physiological and pathological conditions.

\section{Mechanisms of transcriptional regulation by pancRNAs}

The first evidence documenting the presence of noncoding transcripts arising from regions located upstream the TSS came from high throughput experiments where hRrp40, a core component of the human $3^{\prime}$ to $5^{\prime}$ exoribonucleolytic exosome and one of the major RNA degradation complexes, was depleted [11]. In these studies, orientation-specific RT-qPCR performed on RNA from either hRrp40 depleted- or control cells demonstrated that both sense and antisense transcripts were detectable upstream the TSS, and the transcribed region was characterized by markers of active transcription, such as RNA polymerase II (RNAPII) and acetylated histone 3 (H3K9ac) peaks [11]. Genome-wide and global nuclear run on sequencing confirmed the presence of a population of low-copy small RNAs transcribed from promoter regions of the mammalian genome, shorter than $200 \mathrm{nu}$ cleotides, and produced by non-overlapping bidirectional transcription sites $[2,3,12]$. Promoter regions are intrinsically bidirectional [13]. Bidirectionality is achieved though the generation of nucleosome depleted regions via recruitment of nucleosome remodeling complexes that stimulate transcription in both directions [14]. However, sense and antisense divergent transcription rates do not correlate [13] and directionality of transcription units is controlled by a number of regulators, including the Chromatin Assembly Factor I (CAF-I) and factors that promote H3K56 acetylation [15], whereas antisense transcription positively correlates with $\mathrm{H} 4$ acetylation [13]. A fascinating hypothesis is that these bidirectional transcripts may act as a RNA reservoir forged by evolutionary pressures to support physiological functions $[16,17]$.

How these noncoding transcripts, both sense and antisense, are involved in the regulation of their host genes is still under investigation, and multiple mechanisms have been proposed, leading either to the activation or repression of the host genes. One hypothesis is that pancRNAs act as mediators of sequence-specific epigenetic changes. To this regard, one proposed molecular mechanism involves the control of CpG (de) methylation, as described for the Sphk1 gene and its Khps1
pancRNA variants [18]. A similar mechanism was observed in mouse embryos, where expression of bidirectional pancRNAs was strongly associated with the upregulation of their host genes during the zygotic genome activation at the 2-cell stage accompanied by sustained DNA demethylation [19], potentially driven by trans-acting factors, such as TET (Ten Eleven-Translocation, Methylcytosine Dioxygenase) proteins, to achieve a sequence-specific DNA demethylation (Fig. 1a).

An alternative, but not mutually exclusive possibility, is that pancRNAs display a more general function, facilitating rapid activation or repression of the downstream gene by altering chromatin structure or by recruiting transcription regulators. Short RNAs originating within 700 base pairs (bp) upstream the TSS of genes targeted by Polycomb were identified in primary $\mathrm{T}$ cells and embryonic stem cells [20]. These RNAs form a stem-loop structure interacting with SUZ12, a component of the Polycomb repressive complex 2 (PRC2). Recruitment of the complex achieves histone H3 Lys27 trimethylation (H3K27me3) thus causing repression of the gene [20, 21] (Fig. 1b).

Another functional model derives from initial work performed in S. pombe [22] and confirmed in humans [23], where the pancRNAs variants are involved in RNA-mediated contribution to the recruitment of transcription factors to enhancers and promoters. This model would suggest that bidirectional transcription of active enhancers and promoters evolved to facilitate trapping of transcription factors at specific regulatory elements, producing a positive feedback loop that contribute to the establishment of gene expression programs (Fig. 1c).

In a further model, the RNAPII reading through the promoter allows transcription of low copy pancRNAs targeted by antisense RNAs. The pancRNAs and antisense RNA form a complex that associate with the local chromatin architecture through a chromatin remodeling complex presumably containing histone methyltransferase DNMT3A. Remarkably, the antisense RNAspancRNAs form RNA:RNA hybrids that create docking sites for the recruitment of gene silencing complexes $[24,25]$. In particular, in this model pancRNAs containing an extended 5' UTR are recognized by endogenous antisense RNAs during RNAPII-mediated transcription of the RNA-targeted promoter. The antisense strand guides a silencing complex composed by DNMT3A, Ago-1, HDAC-1, and/or EZH2 to the targeted promoter (Fig. 1d). Next, the antisense RNA-targeted promoter may result in heterochromatinization of the local siRNA-targeted genomic region, exhibiting a silent shape, marked by both histone H3 lysine-9 dimethylation (H3K9me2) and histone $\mathrm{H} 3$ lysine-27 trimethylation (H3K27me3) [24]. 


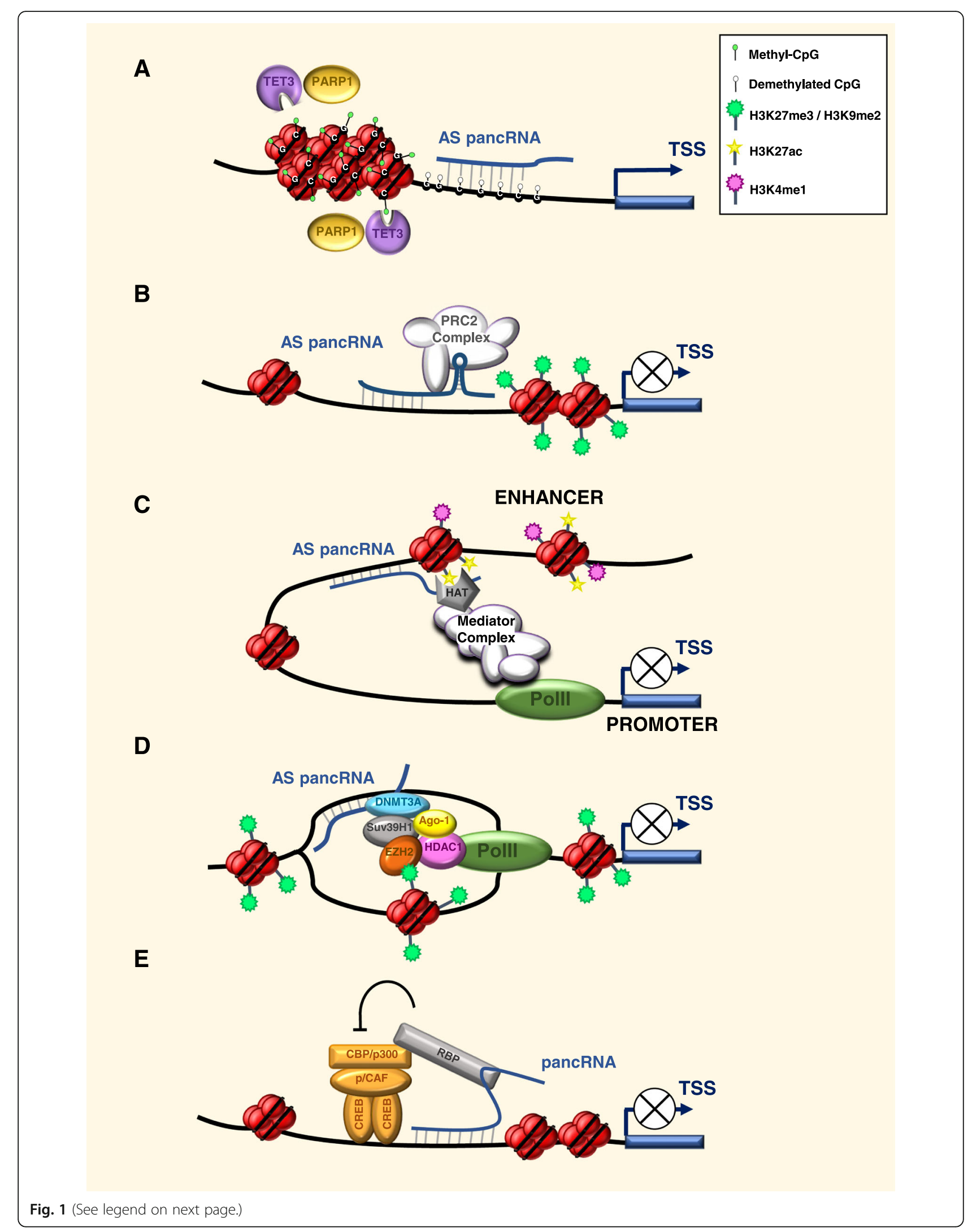


(See figure on previous page.)

Fig. 1 Hypothetical models to explain sense and antisense pancRNA (AS pancRNA) activities. a pancRNAs act in concert with PARP1 and TET3 factors to establish the hypomethylated state of $\mathrm{CpG}$ islands within the promoter, thus activating in cis the transcription of the host gene. $\mathbf{b}$ AS pancRNAs recruit Polycomb repressive complex PRC2, catalyzing the trimethylation of histone $\mathrm{H} 3$ at K27 and the chromatin packaging. c AS pancRNAs can bind histone acetylases and methylases that open the chromatin, allowing the engagement of the Mediator Complex and the chromatin looping. $\mathbf{d}$ Antisense pancRNAs tight on the promoter an epigenetic silencing complex formed by Ago-1, DNMT3a, EZH2, Suv39H1 and $\mathrm{HDAC1}$, which causes trimethylation of histone $\mathrm{H} 3$ at $\mathrm{K} 27$, heterochromatin formation and repression of transcription. e pancRNAs can bind RNA binding proteins (including FUS/TLS and Sam68), thus promoting inhibition of the histone acetyltransferase activity of the p300/CREB binding protein (CBP)-associated factor (PCAF) and resulting in the suppression of transcription

In addition to RNAPII, pancRNAs transcribed by RNAPI in the nucleolus have been shown to take part to regulatory networks controlling the epigenetic state of chromatin of ribosomal genes. These pancRNAs form a DNA:RNA triplex recognized by the DNA methyltransferase DNMT3B to achieve de novo CpG methylation of rRNA genes (rDNA) [26]. The formation of DNA-RNA hybrid structures has been proposed to explain the unmethylated status of most human CpG islands in promoter regions. Unlike the previous model, unmethylated CpG promoters in the human genome show strand asymmetry in the distribution of guanine and cytosines, a property known as "GC skew". This property confers the ability to form stable, threestranded structures called R-loops upon RNA transcription. R-loop formation at promoters can prevent binding of DNMT3B and, therefore, DNA methylation [27].

Another mechanism proposed for pancRNA function has been illustrated for the cyclin D1 gene (CCND1) [28, 29]. Wang and colleagues described DNA damage-driven pancRNAs transcribed in HeLa cells from the region upstream the TSS of CCND1 gene. The authors showed that the pancCCND1_D was able to recruit the RNA binding protein FUS and CBP/ p300, thus inhibiting the histone acetyl transferase (HAT) activity, resulting in CCND1 repression (Fig. 1e). Similarly, Palombo and colleagues described a cognate pancRNA transcribed from the same region, the pancCCND1_B, expressed in Ewing sarcoma and actively recruiting a multimolecular complex composed by the RNA binding protein Sam68 and the RNA/ DNA helicase DHX9 to inhibit CCND1 transcription [29]. These studies highlight the possibility that multiple transcripts driven by the same promoter can synergistically act in cis to achieve activation or repression of the host gene, or even play antagonistic functions.

Although initial models focused on pancRNAs involved in the epigenetic silencing of nearby genes, later on genome-wide efforts demonstrated a positive correlation between the expression of pancRNAs and the neighboring protein-coding genes [30, 31]. The emerging scenario indicates both enhancing and repressive activities exerted by pancRNAs on their host target genes depending on the intrinsic characteristics of each pancRNA and on the regulatory features imposed by the local chromatin conformation.
pancRNAs: regulators of transcription in developmental processes

In the past few years, pancRNAs have been shown to cover crucial roles in the guidance of cell differentiation $[18,19,32,33]$. Transcriptome profiling of human and murine embryonic stem cells revealed that more than $60 \%$ of the lncRNA derive from divergent transcription at the promoters of protein-coding genes. Analysis of the distribution of these divergent pancRNAs revealed that their position in the genome is not casual, but it is correlated with protein-coding genes enriched in functions linked to developmental processes [34]. In fact, the pancRNA/mRNA gene pairs undergo coordinated transcriptional changes during the differentiation of the human embryonic stem cells toward endoderm [23]. Furthermore, transcriptome signatures revealed that bidirectional pancRNAs display different expressions pattern in human fetal and adult heart, due to a fine-tuned orchestration of specific epigenetic modifications, suggesting that pancRNAs which show a mutual expression with their neighboring genes, may contribute to the fetal heart development [35].

It is well known that promoters with a high CpG content can undergo bidirectional transcription and that divergent IncRNAs are capable to positively regulate in cis the transcription of the nearby coding genes, by contributing to their epigenetic setting [33]. As mentioned above, one of the first evidence documenting the modulation of gene expression depending on the bidirectional activity and the methylation status of the promoter was provided for the sphingosine kinase 1 (Sphk1) gene, in primary cells from rat fetuses [18]. Sphingosine kinase 1 is involved in the differentiation of fibroblast and keratinocytes, as well as in vascular and neural development. The Sphk1 CpG island contains a regulatory element, indicated as tissue-dependent differentially methylated region (T-DMR), involved in the regulation of Sphk1 expression. Transcription of the antisense pancRNA Khps1 from the promoter induces DNA demethylation at CG sites, specifically in the T-DMR of $\operatorname{Sph} k 1$, thus inducing de-repression of the gene [18]. A further proof that pancRNAs can induce the demethylation of $\mathrm{CpG}$ islands upstream the partnered ORF, came later from a study conducted in normal rat kidney epithelial cells and undifferentiated PC12 rat cell line [32]. This function of 
the pancRNAs has been demonstrated as essential for the zygotic gene activation and the acquisition of pluripotency in mouse early embryos but also for meso- and endodermal differentiation of pluripotent murine embryonic stem cells $[19,36]$. Initially, in mouse preimplantation embryos, the pancRNA pancIl17d turned out to be responsible for triggering the expression of the interleukin $17 \mathrm{~d}$, indispensable for successful formation of the blastocyst. Although the expression of this pancRNA was associated with an increased DNA demethylation at the promoter, the molecular mechanism underlying this regulation was not further characterized. The epigenetic modifications associated to the zygotic gene activation was assumed to be due to the enrollment of PARP and TET3 demethylation factors on chromatin by pancRNAs or to be possibly only an indirect upshot $[19,37]$.

In addition, it has been proposed that pancRNAs might bind epigenetic factors, promoting the fold of the chromatin into a transcriptionally competent ternary structure, named R-Loop and composed by the nascent RNA annealed with its complementary ssDNA and the nontemplate ssDNA. Another possibility was that pancRNAs may perhaps stabilize the active state of chromatin through the association with small dsRNAs, which in turn, could cover the catalytic site of methyl transferases [38].

A subsequent investigation carried out in murine ESC, underlined the requirement of Evxlas IncRNA for the transcriptional activation of the neighboring proteincoding gene $E V X 1$, essential for mesoderm differentiation [36]. In this case, the authors successfully demonstrated that the pancRNA binds an enhancer site on its locus and enables the recruitment of the transcription co-activator Mediator on the promoter [36]. Mediator thus coordinates the enhancer-promoter gene loop required for the assembly of the transcription machinery (Fig. 1c) [36].

Coupled expression of pancRNAs and the relative mRNAs in differentiating cells is often supported by the enrichment of histone acetylation and methylation in the promoter [34]. The terminal differentiation of PC12 cells is cAMP-dependent and relies on the fine-tuned expression of several pancRNAs deriving from bidirectional promoters enriched in cAMP response elements [39]. Among them, pancNusap1 positively regulates the expression of the spindle-associate gene Nusap1, and this effect is accompanied by an increased acetylation of $\mathrm{H} 3$ lysine 9 and 27 at the promoter [39]. The stimulation with cAMP induces a CRE-mediated concerted repression of pancNusap1 and Nusap1, resulting in the inhibition of the $\mathrm{M}$-phase and the irreversible cell cycle withdrawal [39]. Similarly, Uph1 pancRNA regulates in cis the transcription of its paired coding gene Hand 2 by enhancing the histone modifications H3K4me1 and H3K27ac in the enhancer [40]. The function of Uhp is critical for heart development in mice embryos, as demonstrated by the severe cardiac defects of $U p h-/-$ mice, leading to embryonic lethality at stage E10.5 [40]. A possible mechanism explaining the increased histone acetylation comes from recent data documenting that during myogenic differentiation, the pancRNA Myoparr binds the myogenin shared promoter and physically interacts with the transcriptional co-activator DDX17 and the histone acetylase PCAF. This association leads to increased H3K27 acetylation of the promoter and the subsequent recruitment of the transcription factor MYOD1 [41]. This also allows the maximum occupancy of the RNAPII on the Myogenin locus, contributing to the exit of myoblasts from cell cycle and promoting differentiation [41].

Remarkably, recruitment of the Mediator complex on the EVX1 promoter is associated to the H3K27ac and H3K4me1 histone modifications [36], where the histone acetylases recruited by the antisense pancRNA empower the access of Mediator. Some antisense poly(A) + pancRNAs from bidirectional promoters can also antagonize the transcription of their relative sense mRNAs. As an example, the pancRNA $h T A P A S$ represses the gene encoding human telomerase reverse transcriptase (hTERT). In the germline and human embryonic stem cell line hTAPAS is fundamental for keeping low the concentration of the TERT protein, guarantying telomere length homeostasis and proliferative potential in the cells [42]. It is interesting to note that some antisense pancRNAs do not regulate the expression of the nearby locus, but can modulate in trans the transcription of other genes, by functionally interacting with the protein encoded from their cognate sense transcript, as for the pancRNA Six3OS, that modulates the activity of the transcriptional factor SIX3, by linking chromatin-modifying enzyme complexes on the SIX3 target genes [43]. This mechanism seems required for cell specification in the postnatal retina and the correct eye development in mice [43]. Interestingly, in the crustacean Daphnia magna it has been recently characterized the sense capped but nonpolyadenylated pancRNA DAPALR, that can activate in trans the transcription of the downstream locus $d s x 1$, relevant for sex determination during embryogenesis [6]. The molecular mechanism underlying the action of $D A P A L R$ is still unclear, but this discovery denotes that the developmental role of pancRNAs is conserved in all eukaryotes although displaying diversification for directionality of transcription, post-transcriptional modifications and mechanism of action. Interestingly, antisense lncRNAs and sense transcripts tend to have a concerted expression in a tissue-specific fashion in fully developed organs, including cerebral cortex, cerebellum, heart, kidney and liver [33,34]. This trend is conserved between mammalian species (chimpanzee, macaque, marmoset, mouse and rat), suggesting that pancRNAs participate in 
the maintenance of tissue homeostasis in adults [33, 34]. To this regard, it has been shown that pancRNAs undergo a strong activation and are involved in the response to oxidative stress in somatic cells [44]. In particular, after exposure to reactive oxygen species, pancRNAs associate with polysomes in the cytoplasm and compete with mRNAs, lowering the translational efficiency and favoring stress adaptation [44].

All these evidences support the idea that pancRNAs display evolutionary conserved functions emblematic both for differentiation and homeostasis in all eukaryotes.

\section{Cancer-related scaffolding function of pancRNAs}

Alterations of pancRNAs have been extensively linked to the changes of gene expression programs occurring in human cancer. PancRNAs affect epigenetic modification of promoters through scaffolding function. It has been shown that non-protein coding transcripts display key roles in cancer biology by impacting the gene expression of important regulatory proteins [45]. In particular, emerging evidences report the ability of ncRNAs to fold into a tertiary structure providing a scaffold for other proteins or regulatory molecules, including RNAs [45].

It is well established the oncogene-like role of pancRNAs in tumorigenesis through the control of critical cell cycle regulators like cyclins $[28,29]$. In response to DNA damage such as ionizing irradiation (IR), the CCND1 pancRNAs are transcribed and negatively regulate cyclin D1 expression [28]. In HeLa cells, pancRNAs transcribed from the promoter of CCND1 gene associate with and recruit the RNA binding protein FUS/TLS (Fused in sarcoma, Translocated in liposarcoma). The localization of the pancRNA_CCND1-FUS complex to the CCND1 promoter results in the inhibition of the $\mathrm{CBP} / \mathrm{p} 300$ histone acetyltransferases activity thereby preventing CCND1 transcription [28]. More recently, a similar repression of the cyclin D1 expression mediated by a protein-RNA complex was described in Ewing sarcoma cells [29]. A deep investigation of the molecular mechanisms underlying this regulation showed that after mitogenic stimuli, such as IGF-1 treatment, the protein partners EWS-FLI1 and DHX9 interact promoting the transcription of target genes, such as CCND1. Perturbation of the EWS-FLI1/DHX9 interaction by the small molecule YK-4-279 causes the formation of an alternative inhibitory complex composed by the RNA binding protein Sam68, DHX9, and the pancRNA_ $C C N D 1 \_B$ determining a repressive chromatin environment responsible of cyclin D1 transcriptional inhibition. The ability of pancRNAs_CCDN1 to affect cell proliferation through transcriptional regulation of CCND1 reveals the contribution of these molecules in the control of cell cycle progression and in the tumorigenic process [29].

A similar mechanism has been documented for the pancRNA_Ets-1, displaying a role in the promotion of in vivo/in vitro growth and aggressiveness of gastric cancer [46]. PancRNA_Ets-1 facilitates the physical interaction between the RNA binding protein NONO and the transcriptional factor ERG, resulting in transactivation of ERG and increased cancer-related gene transcription [46]. Moreover, pancRNA_Ets-1 displays a crucial role in neuroblastoma tumorigenesis, by promoting neuroblastoma cell growth, invasion and metastasis. PancRNA_Ets-1 binds to the heterogeneous nuclear ribonucleoprotein $\mathrm{K}$ (hnRNPK) to facilitate its physical interaction with $\beta$-catenin, resulting in reduced $\beta$ catenin proteasome-dependent degradation [47]. As a consequence, the enhanced nuclear translocation of $\beta$ catenin affects its gene transcriptional program contributing to neuroblastoma progression. Notably, pancRNA Ets-1 upregulation in clinical tissues and cell lines of both gastric cancer and neuroblastoma could be exploited as promising markers and potential therapeutic targets.

\section{RNA-directed transcriptional gene regulation by pancRNAs in cancer}

The pancRNA_FOXCUT is transcribed upstream of the Forkhead box C1 (FOXC1) gene and its expression is positively correlated with FOXC1 mRNA [48]. The transcription factor FOXC1 is a key regulator of several biological processes and its abnormal expression was found associated to poor survival in various malignant tumors and in the epithelial to mesenchymal transition (EMT) process $[24,49,50]$. Recent studies showed that the FOXCUTFOXC1 regulatory network is associated with tumorigenesis and cancer progression in esophageal squamous cell carcinoma (ESCC) [50], oral squamous cell carcinoma (OSCC) [51] and nasopharyngeal carcinoma (NPC) [52]. FOXCUT expression was found enhanced in Basal-Like Breast Cancers (BLBCs) but not in other non-basal like breast cancer subtypes, suggesting that FOXCUT may function as specific biomarker in BLBCs [53]. Notably, in all these different tumor contexts, knockdown of FOXCUT reduced the levels of FOXC1 mRNA, concurring with the observed inhibition of migration, invasion and the metastatic potential of cells.

Similarly, the expression of the pancRNA_HIF2PUT (HIF2PUT) was found correlated with the expression of the hypoxia-inducible factor- $2 \alpha$ (HIF- $2 \alpha$ ), in osteosarcoma patients $[54,55]$. HIF- $2 \alpha$ has been associated with stem-like properties in stem cells and in cancer stem cells of different types of tumor [46, 56, 57]. Moreover, HIF2PUT knockdown is able to induce enhanced proliferation, migration and self-renewal of MG63 cells, 
Table 1 List of pancRNAs identified in cancer

\begin{tabular}{|c|c|c|c|c|}
\hline Name & Cancer Type & Proposed Mechanism & Downstream Effects & Ref. \\
\hline \multirow[t]{2}{*}{ pancRNAs_CCDN1 } & Cervical cancer & $\begin{array}{l}\text { Inhibition of CBP/p300 HAT activity } \\
\text { by pancRNA_CCDN1-FUS complex }\end{array}$ & \multirow[t]{2}{*}{ Repression of Cyclin D1 expression } & [28] \\
\hline & Ewing sarcoma & $\begin{array}{l}\text { The pancRNA_CCND1_B/Sam68/DHX9 } \\
\text { complex determines a repressive } \\
\text { chromatin environment }\end{array}$ & & [29] \\
\hline \multirow[t]{2}{*}{ pancRNA_Ets-1 } & Gastric cancer & $\begin{array}{l}\text { NONO-pancRNA_Ets-1 complex interacts } \\
\text { with ERG }\end{array}$ & $\begin{array}{l}\text { Activation of ERG-related gene } \\
\text { transcription }\end{array}$ & [46] \\
\hline & Neuroblastoma & $\begin{array}{l}\text { Interaction between pancRNA_Ets-1/hnRNPK } \\
\text { complex and } \beta \text {-catenin }\end{array}$ & $\begin{array}{l}\text { Enhanced } \beta \text {-catenin transcriptional } \\
\text { activity }\end{array}$ & [47] \\
\hline \multirow[t]{4}{*}{ FOXCUT } & Esophageal squamous cancer & \multirow[t]{4}{*}{ Unknown } & \multirow{4}{*}{$\begin{array}{l}\text { Positive correlation with FOXC1 } \\
\text { expression }\end{array}$} & [50] \\
\hline & Oral squamous cell carcinoma & & & [51] \\
\hline & Nasopharyngeal carcinoma & & & [52] \\
\hline & Basal-like breast cancer & & & [53] \\
\hline \multirow[t]{2}{*}{ HIF2PUT } & Osteosarcoma & \multirow[t]{2}{*}{ Unknown } & \multirow{2}{*}{$\begin{array}{l}\text { Positive correlation with HIF-2a } \\
\text { expression }\end{array}$} & {$[54,55]$} \\
\hline & Colorectal cancer & & & [58] \\
\hline pancRNA_CDH1 & Prostate cancer & $\begin{array}{l}\text { IsomiR-4534/Ago-pancRNA_CDH1 } \\
\text { recruits SUV39H1 }\end{array}$ & $\mathrm{CDH} 1$ transcriptional repression & [59] \\
\hline \multirow[t]{2}{*}{ pancRNA_VIM } & Colon cancer & \multirow{2}{*}{$\begin{array}{l}\text { R-loop to support an open } \\
\text { chromatin state }\end{array}$} & \multirow[t]{2}{*}{ Enhanced Vimentin transcription } & \multirow[t]{2}{*}{ [60] } \\
\hline & Breast cancer & & & \\
\hline Khps1 & $\begin{array}{l}\text { Cervical cancer, liver cancer and } \\
\text { osteosarcoma }\end{array}$ & $\begin{array}{l}\text { DNA-RNA duplex able to interact } \\
\text { with p300/CBP }\end{array}$ & $\begin{array}{l}\text { Enhanced E2F1-mediated SPHK1 } \\
\text { transcription }\end{array}$ & [61] \\
\hline
\end{tabular}

suggesting that HIF2PUT may suppress the properties of cancer stem cells in osteosarcoma by regulating the expression of HIF-2 $\alpha$ [54]. In colorectal cancer specimens, the expression of HIF $2 P U T$ positively correlates with HIF-2 $\alpha$ expression and HIF2PUT knockdown impairs the stem cell like properties of colorectal cancer stem cells by regulating HIF- $2 \alpha$ expression [58].

In different prostate cancer cell lines and tumors, Pisignano and colleagues showed that the gene encoding E-cadherin $(C D H 1)$, known as an epithelial cell differentiation marker and a tumor suppressor, is epigenetically silenced contributing to the acquisition of key essential properties in the tumor development and progression. They found that a specific miRNA (isomiR-4534) guides the Argonaute1 (Ago1) binding to a precise site on the pancRNA_CDH1. In turn, Ago1 recruits the histone methyltransferase SUV39H1 to repress the promoter activity with the consequent transcriptional suppression. Importantly, a cancer-associated single nucleotide polymorphism (SNP, rs16260) facilitates the accessibility of the miRNA-Ago1 complex to the pancRNA_CDH1, increasing $C D H 1$ gene silencing [59].

As mentioned above, pancRNAs can also be involved in the formation of a RNA:DNA hybrid (named R-loop) to affect gene expression. This kind of mechanism was found in colon cancer cells and in two different breast cancer cell lines, MCF7 and MCF10, where the pancRNA_VIM, an antisense noncoding transcript on Vimentin RNA (deposited as VIM-AS1), supports an open chromatin state by participating to the formation of R-loop. This structure facilitates the accessibility of Vimentin gene to the transcriptional machinery and enhances the NF-K $\beta$ binding to Vimentin promoter, thus resulting in increased gene transcription [60].

Beside the possibility to form a R-loop, pancRNAs may be involved in the formation of a DNA-RNA triplex. Recently, it has been reported that the expression of the proto-oncogene SPHK1, involved in the control of apoptosis, requires a pancRNA, termed Khps1, transcribed in antisense orientation to SPHK1. Khps1 is bound to a homopurine stretch (TFR2), forming a DNARNA duplex able to interact with p300/CBP, thus establishing an open chromatin structure that facilitates the E2F1-mediated SPHK1 transcription [61].

Collectively, these studies (listed in Table 1) suggest a role of pancRNAs in carcinogenesis. The discovery of the precise mechanisms through which these molecules may modulate transcription of cancer-related genes could provide a deeper understanding of the complex integrated network that supports the tumor phenotype.

\section{Conclusions}

Genome-wide transcriptomic analyses have enabled huge advances in the understanding of the intricate 
transcriptional regulatory network driven by cis-acting noncoding transcripts on their target genes, highlighting enhancing and repressive activities exerted by the pancRNAs on target genes [62]. Accumulating evidence shows that changes in the repertoire of pancRNAs finely shape tissue-specific gene expression patterns [34]. Indeed, comparative transcriptome analyses revealed higher diversity of pancRNA- over mRNA-expression profiles, favoring an evolutionary diversification of the transcriptome according to a given species [34]. In parallel, promoter regions of pancRNA-hosting genes exhibit a higher level of sequence conservation than those of pancRNA-lacking genes [34]. Thus, pancRNAs could represent a new layer of species-dependent gene regulation mechanism that allows and contributes to the dynamic evolutionary process and adaptation of a species.

The differential expression of pancRNAs between tumor and benign specimens suggest their potential usage as diagnostic, prognostic or predictive biomarkers. A fascinating question is whether singlenucleotide polymorphisms (SNPs) in the promoter regions affect the function of these promoter-proximal transcripts, by impacting chromatin dynamics and transcription factor recruitment. To this regard, several disease-associated SNPs map to noncoding regions, including promoters $[63,64]$, but whether pancRNAs are involved in the disease process and the mechanistic link between noncoding SNPs and transcriptional regulation has not been clarified yet, although possible effects of deleting regulatory elements contained within the mutated regions could not be excluded. Furthermore, given the relevance of pancRNAs in developmental processes and in pathological conditions, the potential of the endogenous pancRNA as a therapeutic target could be further evaluated and exploited. For example, forced expression of pancRNAs could be instrumental for artificially manipulating epigenetic modification on specific candidate genes, to accomplish a targeted and functional disruption of aberrant methylation activity, with important implications in transcriptional reprogramming. Conversely, targeted deregulation of pancRNA-based transcriptional network could contribute to epigenetic silencing of tumor suppressor genes and disease progression, thus altering the epigenetic landscape of patients.

Collectively, the reported findings highlight pancRNAs as potential candidates for transcriptional reprogramming. To this regard, the epigenome profile could be rewritten by a set of epigenetic modifiers, including pancRNAs. Manipulations of these molecules could be employed in medical purposes.

\section{Abbreviations}

Ago1: Argonaute1; BLBCs: basal-like breast cancers; CAF-l: Chromatin Assembly Factor I; CCND1: cyclin D1 gene; EMT: epithelial to mesenchymal transition; ESCC: esophageal squamous cell carcinoma; H3K27me3: histone H3 Lys27 trimethylation; H3K27me3: histone H3 lysine-27 tri-methylation; H3K9ac: acetylated histone 3; H3K9me2: H3 lysine-9 di-methylation; HAT: histone acetyl transferase; hnRNPK: heterogeneous nuclear ribonucleoprotein K; NPC: nasopharyngeal carcinoma; OSCC: oral squamous cell carcinoma; pancRNA: Promoter-associated noncoding RNA; RNAPII: RNA polymerase II; SNP: single nucleotide polymorphism; Sphk1: the sphingosine kinase 1; TSS: Transcription Start Site

\section{Acknowledgements}

We would like to express our gratitude to Drs. Ramona Palombo and Neri Mercatelli for helpful discussions.

\section{Authors' contributions}

L.C., V.F. and M.P.P. wrote the manuscript. V.F. prepared the Fig. M.P.P. supervised and guided the entire project. The authors read and approved the final manuscript.

\section{Funding}

This work was supported by grants from the Associazione Italiana Ricerca sul Cancro (AIRC; IG21877) and from Ministry of Health "Ricerca Finalizzata" (RF2016-02363460)

\section{Availability of data and materials \\ Not applicable.}

Ethics approval and consent to participate

Not applicable.

\section{Consent for publication}

All authors agree to submit the article for publication.

\section{Competing interests}

The authors declare that they have no competing interests.

Received: 28 December 2019 Accepted: 25 February 2020

Published online: 17 March 2020

\section{References}

1. Mattick JS. Non-coding RNAs: the architects of eukaryotic complexity. EMBO Rep. 2001;2(11):986-91.

2. Core LJ, Waterfall JJ, Lis JT. Nascent RNA sequencing reveals widespread pausing and divergent initiation at human promoters. Science. 2008; 322(5909):1845-8.

3. Seila AC, Core LJ, Lis JT, Sharp PA. Divergent transcription: a new feature of active promoters. Cell Cycle. 2009;8(16):2557-64.

4. Kapranov P, Cheng J, Dike S, Nix DA, Duttagupta R, Willingham AT, Stadler PF, Hertel J, Hackermüller J, Hofacker IL, Bell I, Cheung E, Drenkow J, Dumais E, Patel S, Helt G, Ganesh M, Ghosh S, Piccolboni A, Sementchenko V, Tammana $H$, Gingeras TR. RNA maps reveal new RNA classes and a possible function for pervasive transcription. Science. 2007;316(5830):1484-8.

5. Martens JA, Laprade L, Winston F. Intergenic transcription is required to repress the Saccharomyces cerevisiae SER3 gene. Nature. 2004;429(6991): $571-4$.

6. Kato Y, Perez CAG, Mohamad Ishak NS, Nong QD, Sudo Y, Matsuura T, Wada T. Watanabe H. A 5' UTR-Overlapping LncRNA Activates the MaleDetermining Gene doublesex1 in the Crustacean Daphnia magna. Curr Biol. 2018;28(11):1811-1817.e4.

7. Kim DH, Sung S. Vernalization-Triggered Intragenic Chromatin Loop Formation by Long Noncoding RNAs. Dev Cell. 2017:40(3):302-312.e4

8. Goh KY, Inoue T. A large transcribed enhancer region regulates $C$. elegans bed-3 and the development of egg laying muscles. Biochim Biophys Acta Gene Regul Mech. 2018;1861(5):519-33.

9. Schor IE, Bussotti G, Maleš M, Forneris M, Viales RR, Enright AJ, Furlong EEM. Non-coding RNA Expression, Function, and Variation during Drosophila Embryogenesis. Curr Biol. 2018;28(22):3547-3561.e9.

10. Guil S, Esteller M. Cis-acting noncoding RNAs: friends and foes. Nat Struct Mol Biol. 2012;19(11):1068-75. 
11. Preker P, Nielsen J, Kammler S, Lykke-Andersen S, Christensen MS, Mapendano CK, Schierup $\mathrm{MH}$, Jensen TH. RNA exosome depletion reveals transcription upstream of active human promoters. Science. 2008;322(5909):1851-4.

12. Flynn RA, Almada AE, Zamudio JR, Sharp PA. Antisense RNA polymerase II divergent transcripts are P-TEFb dependent and substrates for the RNA exosome. Proc Natl Acad Sci U S A. 2011;108(26):10460-5.

13. Churchman LS, Weissman JS. Nascent transcript sequencing visualizes transcription at nucleotide resolution. Nature. 2011;469(7330):368-73.

14. Jin Y, Eser U, Struhl K, Churchman LS. The Ground State and Evolution of Promoter Region Directionality. Cell. 2017;170(5):889-898.e10.

15. Marquardt S, Escalante-Chong R, Pho N, Wang J, Churchman LS, Springer M, Buratowski S. A chromatin-based mechanism for limiting divergent noncoding transcription. Cell. 2014;158(2):462.

16. Wu X, Sharp PA. Divergent transcription: a driving force for new gene origination? Cell. 2013;155(5):990-6.

17. Churchman LS. Not just noise: genomics and genetics bring long noncoding RNAs into focus. Mol Cell. 2017;65(1):1-2.

18. Imamura T, Yamamoto S, Ohgane J, Hattori N, Tanaka S, Shiota K. Noncoding RNA directed DNA demethylation of Sphk1 CpG island. Biochem Biophys Res Commun. 2004;322(2):593-600.

19. Hamazaki N, Uesaka M, Nakashima K, Agata K, Imamura T. Gene activationassociated long noncoding RNAs function in mouse preimplantation development. Development. 2015;142(5):910-20.

20. Kanhere A, Viiri K, Araújo CC, Rasaiyaah J, Bouwman RD, Whyte WA, Pereira CF, Brookes E, Walker K, Bell GW, Pombo A, Fisher AG, Young RA, Jenner RG. Short RNAs are transcribed from repressed polycomb target genes and interact with polycomb repressive complex-2. Mol Cell. 2010;38(5):675-88.

21. Mai H, Zhou B, Liu L, Yang F, Conran C, Ji Y, Hou J, Jiang D. Correction to: molecular pattern of IncRNAs in hepatocellular carcinoma. J Exp Clin Cancer Res. 2019;38(1):352.

22. Hirota K, Miyoshi T, Kugou K, Hoffman CS, Shibata T, Ohta K. Stepwise chromatin remodelling by a cascade of transcription initiation of noncoding RNAs. Nature. 2008;456(7218):130-4.

23. Sigova AA, Mullen AC, Molinie B, Gupta S, Orlando DA, Guenther MG, Almada AE, Lin C, Sharp PA, Giallourakis CC, Young RA. Divergent transcription of long noncoding RNA/mRNA gene pairs in embryonic stem cells. Proc Natl Acad Sci U S A. 2013;110(8):2876-81.

24. Han J, Kim D, Morris KV. Promoter-associated RNA is required for RNAdirected transcriptional gene silencing in human cells. Proc Natl Acad Sci U S A. 2007;104(30):12422-7.

25. Schwartz JC, Younger ST, Nguyen NB, Hardy DB, Monia BP, Corey DR, Janowski BA. Antisense transcripts are targets for activating small RNAs. Nat Struct Mol Biol. 2008;15(8):842-8.

26. Schmitz KM, Mayer C, Postepska A, Grummt I. Interaction of noncoding RNA with the rDNA promoter mediates recruitment of DNMT3b and silencing of rRNA genes. Genes Dev. 2010;24(20):2264-9.

27. Ginno PA, Lott PL, Christensen HC, Korf I, Chédin F. R-loop formation is a distinctive characteristic of unmethylated human $\mathrm{CpG}$ island promoters. Mol Cell. 2012;45(6):814-25.

28. Wang X, Arai S, Song X, Reichart D, Du K, Pascual G, Tempst P, Rosenfeld MG, Glass CK, Kurokawa R. Induced ncRNAs allosterically modify RNA-binding proteins in cis to inhibit transcription. Nature. 2008;454(7200):126-30.

29. Palombo R, Frisone P, Fidaleo M, Mercatelli N, Sette C, Paronetto MP. The promoter associated non-coding RNA pncCCND1_B assembles a proteinRNA complex to regulate cyclin D1 transcription in Ewing sarcoma. Cancer Res. 2019;79(14):3570-82.

30. Guttman M, Amit I, Garber M, French C, Lin MF, Feldser D, Huarte M, Zuk O, Carey BW, Cassady JP, Cabili MN, Jaenisch R, Mikkelsen TS, Jacks T, Hacohen $\mathrm{N}$, Bernstein BE, Kellis M, Regev A, Rinn JL, Lander ES. Chromatin signature reveals over a thousand highly conserved large non-coding RNAs in mammals. Nature. 2009:458(7235):223-7.

31. Cabili MN, Trapnell C, Goff L, Koziol M, Tazon-Vega B, Regev A, Rinn JL. Integrative annotation of human large intergenic noncoding RNAs reveals global properties and specific subclasses. Genes Dev. 2011;25(18):1915-27.

32. Tomikawa J, Shimokawa H, Uesaka M, Yamamoto N, Mori Y, Tsukamura H, Maeda K, Imamura T. Single-stranded noncoding RNAs mediate local epigenetic alterations at gene promoters in rat cell lines. J Biol Chem. 2011; 286(40):34788-99.

33. Uesaka M, Nishimura O, Go Y, Nakashima K, Agata K, Imamura T. Bidirectional promoters are the major source of gene activation-associated non-coding RNAs in mammals. BMC Genomics. 2014;15:35.
34. Uesaka M, Agata K, Oishi T, Nakashima K, Imamura T. Evolutionary acquisition of promoter-associated non-coding RNA (pancRNA) repertoires diversifies species-dependent gene activation mechanisms in mammals. BMC Genomics. 2017;18(1):285.

35. He C, Hu H, Wilson KD, Wu H, Feng J, Xia S, Churko J, Qu K, Chang HY, Wu JC. Systematic characterization of long noncoding RNAs reveals the contrasting coordination of Cis- and trans-molecular regulation in human fetal and adult hearts. Circ Cardiovasc Genet. 2016;9(2):110-8.

36. Luo S, Lu JY, Liu L, Yin Y, Chen C, Han X, Wu B, Xu R, Liu W, Yan P, Shao W, Lu Z, Li H, Na J, Tang F, Wang J, Zhang YE, Shen X. Divergent IncRNAs regulate gene expression and lineage differentiation in pluripotent cells. Cell Stem Cell. 2016;18(5):637-52.

37. Hamazaki N, Nakashima K, Imamura T. Manipulation of promoter-associated noncoding RNAs in mouse early embryos for controlling sequence-specific epigenetic status. Methods Mol Biol. 2017;1543:271-82

38. Imamura T, Uesaka M, Nakashima K. Epigenetic setting and reprogramming for neural cell fate determination and differentiation. Philos Trans R Soc Lond Ser B Biol Sci. 2014;369(1652).

39. Yamamoto N, Agata K, Nakashima K, Imamura T. Bidirectional promoters link CAMP signaling with irreversible differentiation through promoterassociated non-coding RNA (pancRNA) expression in PC12 cells. Nucleic Acids Res. 2016;44(11):5105-22.

40. Anderson KM, Anderson DM, McAnally JR, Shelton JM, Bassel-Duby R, Olson EN. Transcription of the non-coding RNA upperhand controls Hand2 expression and heart development. Nature. 2016;539(7629):433-6.

41. Hitachi K, Nakatani M, Takasaki A, Ouchi Y, Uezumi A, Ageta H, Inagaki H, Kurahashi H, Tsuchida K. Promoter-associated IncRNA. EMBO Rep. 2019;20(3).

42. Malhotra S, Freeberg MA, Winans SJ, Taylor J, Beemon KL. A novel long non-coding RNA in the hTERT promoter region regulates hTERT expression. Noncoding RNA. 2017;4(1)

43. Rapicavoli NA, Poth EM, Zhu H, Blackshaw S. The long noncoding RNA Six3OS acts in trans to regulate retinal development by modulating Six3 activity. Neural Dev. 2011;6:32.

44. Giannakakis A, Zhang J, Jenjaroenpun P, Nama S, Zainolabidin N, Aau MY, Yarmishyn AA, Vaz C, Ivshina AV, Grinchuk OV, Voorhoeve M, Vardy LA, Sampath P, Kuznetsov VA, Kurochkin IV, Guccione E. Contrasting expression patterns of coding and noncoding parts of the human genome upon oxidative stress. Sci Rep. 2015;5:9737.

45. Kumar MM, Goyal R. LncRNA as a therapeutic target for angiogenesis. Curr Top Med Chem. 2017;17(15):1750-7.

46. Li D, Chen Y, Mei H, Jiao W, Song H, Ye L, Fang E, Wang X, Yang F, Huang $\mathrm{K}$, Zheng $\mathrm{L}$, Tong Q. Ets-1 promoter-associated noncoding RNA regulates the NONO/ERG/Ets-1 axis to drive gastric cancer progression. Oncogene. 2018;37(35):4871-86.

47. Li D, Wang X, Mei H, Fang E, Ye L, Song H, Yang F, Li H, Huang K, Zheng L, Tong Q. Long noncoding RNA pancEts-1 promotes neuroblastoma progression through hnRNPK-mediated $\beta$-catenin stabilization. Cancer Res. 2018;78(5):1169-83.

48. Yang Z, Jiang S, Cheng Y, Li T, Hu W, Ma Z, Chen F, Yang Y. FOXC1 in cancer development and therapy: deciphering its emerging and divergent roles. Ther Adv Med Oncol. 2017:9(12):797-816.

49. Cao S, Wang Z, Gao X, He W, Cai Y, Chen H, Xu R. FOXC1 induces cancer stem cell-like properties through upregulation of beta-catenin in NSCLC. J Exp Clin Cancer Res. 2018;37(1):220.

50. Pan F, Yao J, Chen Y, Zhou C, Geng P, Mao H, Fang X. A novel long noncoding RNA FOXCUT and mRNA FOXC1 pair promote progression and predict poor prognosis in esophageal squamous cell carcinoma. Int J Clin Exp Pathol. 2014;7(6):2838-49.

51. Kong XP, Yao J, Luo W, Feng FK, Ma JT, Ren YP, Wang DL, Bu RF. The expression and functional role of a FOXC1 related mRNA-IncRNA pair in oral squamous cell carcinoma. Mol Cell Biochem. 2014;394(1-2):177-86.

52. Xu YZ, Chen FF, Zhang Y, Zhao QF, Guan XL, Wang HY, Li A, Lv X, Song SS, Zhou Y, Li XJ. The long noncoding RNA FOXCUT promotes proliferation and migration by targeting FOXC1 in nasopharyngeal carcinoma. Tumour Biol. 2017;39(6):1010428317706054.

53. Liu J, Shen L, Yao J, Li Y, Wang Y, Chen H, Geng P. Forkhead box C1 promoter upstream transcript, a novel long non-coding RNA, regulates proliferation and migration in basal-like breast cancer. Mol Med Rep. 2015; 11(4):3155-9.

54. Wang $Y$, Yao J, Meng $H$, Yu Z, Wang Z, Yuan $X$, Chen $H$, Wang A. A novel long non-coding RNA, hypoxia-inducible factor-2a promoter upstream 
transcript, functions as an inhibitor of osteosarcoma stem cells in vitro. Mol Med Rep. 2015;11(4):2534-40.

55. Zhao D, Wang S, Chu X, Han D. LncRNA HIF2PUT inhibited osteosarcoma stem cells proliferation, migration and invasion by regulating HIF2 expression. Artif Cells Nanomed Biotechnol. 2019;47(1):1342-8.

56. Yang J, Zhang X, Zhang Y, Zhu D, Zhang L, Li Y, Zhu Y, Li D, Zhou J. HIF-2a promotes epithelial-mesenchymal transition through regulating Twist2 binding to the promoter of E-cadherin in pancreatic cancer. J Exp Clin Cancer Res. 2016;35:26.

57. Yan L, Xu F, Dai CL. Relationship between epithelial-to-mesenchymal transition and the inflammatory microenvironment of hepatocellular carcinoma. J Exp Clin Cancer Res. 2018;37(1):203.

58. Yao J, Li J, Geng P, Li Y, Chen H, Zhu Y. Knockdown of a HIF-2a promoter upstream long noncoding RNA impairs colorectal cancer stem cell properties in vitro through HIF-2a downregulation. Onco Targets Ther. 2015; 8:3467-74.

59. Pisignano G, Napoli S, Magistri M, Mapelli SN, Pastori C, Di Marco S, Civenni G, Albino D, Enriquez C, Allegrini S, Mitra A, D'Ambrosio G, Mello-Grand M, Chiorino G, Garcia-Escudero R, Varani G, Carbone GM, Catapano CV. A promoter-proximal transcript targeted by genetic polymorphism controls E-cadherin silencing in human cancers. Nat Commun. 2017:8:15622.

60. Boque-Sastre R, Soler M, Oliveira-Mateos C, Portela A, Moutinho C, Sayols S, Villanueva A, Esteller M, Guil S. Head-to-head antisense transcription and Bloop formation promotes transcriptional activation. Proc Natl Acad Sci U S A. 2015:112(18):5785-90

61. Postepska-lgielska A, Giwojna A, Gasri-Plotnitsky L, Schmitt N, Dold A, Ginsberg D, Grummt I. LncRNA Khps1 regulates expression of the protooncogene SPHK1 via triplex-mediated changes in chromatin structure. Mol Cell. 2015;60(4):626-36.

62. Bogu GK, Vizán P, Stanton LW, Beato M, Di Croce L, Marti-Renom MA. Chromatin and RNA maps reveal regulatory long noncoding RNAs in mouse. Mol Cell Biol. 2015;36(5):809-19.

63. M.T. Maurano, R. Humbert, E. Rynes, R.E. Thurman, E. Haugen, H. Wang, A.P. Reynolds, R. Sandstrom, H. Qu, J. Brody, A. Shafer, F. Neri, K. Lee, T. Kutyavin, S. Stehling-Sun, A.K. Johnson, T.K. Canfield, E. Giste, M. Diegel, D. Bates, R.S. Hansen, S. Neph, P.J. Sabo, S. Heimfeld, A. Raubitschek, S. Ziegler, C. Cotsapas, N. Sotoodehnia, I. Glass, S.R. Sunyaev, R. Kaul, J.A. Stamatoyannopoulos, Systematic localization of common disease-associated variation in regulatory DNA, Science 337(6099) (2012) 1190-5.

64. Nguyen Q, Carninci P. Expression specificity of disease-associated IncRNAs: toward personalized medicine. Curr Top Microbiol Immunol. 2016;394:237-58.

\section{Publisher's Note}

Springer Nature remains neutral with regard to jurisdictional claims in published maps and institutional affiliations.

Ready to submit your research? Choose BMC and benefit from:

- fast, convenient online submission

- thorough peer review by experienced researchers in your field

- rapid publication on acceptance

- support for research data, including large and complex data types

- gold Open Access which fosters wider collaboration and increased citations

- maximum visibility for your research: over $100 \mathrm{M}$ website views per year

At $\mathrm{BMC}$, research is always in progress.

Learn more biomedcentral.com/submissions 